Original Article

\title{
Evaluation of Redox Status in Patients with Hepatitis B Virus in Zahedan, Iran
}

\author{
Hosnie Hoseini $^{* 1}$, Soudabeh Etemadi ${ }^{2,3}$
}

1.Department of Laboratory Sciences, Zahedan Branch, Islamic Azad University, Zahedan , Iran

2.Infectious Diseases and Tropical Medicine Research Center, Resistant Tuberculosis Institute, Zahedan University of Medical Sciences, Zahedan, Iran

1.Department of Parasitology and Mycology, Faculty of Medicine, Zahedan University of Medical Sciences, Zahedan, Iran

*Correspondence: Hosnie Hoseini, Department of Laboratory Sciences, Zahedan Branch, Islamic Azad University, Zahedan, Iran

Tel: +989211541347

Email: hosniehoseini@gmail.com

Received August 20, 2020

Accepted August 26, 2020

\begin{abstract}
Background and objectives: Redox status can be defined as an increase in oxidant and/or a decrease in antioxidant capacities. There is limited information about the redox status of patients with hepatitis B virus (HBV) infection. Therefore, we aimed to evaluate the redox status of patients with HBV infection in Zahedan, Southeast of Iran.

Methods: This study was carried out in 2019 on $25 \mathrm{HBV}$ patients and 25 healthy individuals. The level of malondialdehyde (MDA) was measured as a marker of lipid peroxidation. Superoxide dismutase (SOD) activity was also measured. Data were analyzed using SPSS software (version 17) at significance of 0.05 .

Results: The MDA level in patients $(5.3 \pm 2.511 \mathrm{n} / \mathrm{ml})$ was significantly higher than in controls $(3.48 \pm 0.516 \mathrm{n} / \mathrm{ml})(\mathrm{P}<0.01)$. Moreover, SOD activity was significantly lower in HBV patients $(125.05 \pm 55.545 \mathrm{n} / \mu \mathrm{l})$ compared to healthy controls $(271 \pm 74.236 \mathrm{n} / \mu \mathrm{l})(\mathrm{P}<0.01)$.

Conclusion: Our results show that patients with HBV infection have higher serum MDA level and lower SOD activity compared to healthy individuals. This can cause liver damage and aggravate the complications in hepatitis B patients.
\end{abstract}

Keywords: Redox status; hepatitis B; malondialdehyde; superoxide dismutase

DOI: $10.29252 / \mathrm{Jcbr} .4 .3 .10$ 


\section{INTRODUCTION}

Hepatocellular carcinoma (HCC) is one of the most common cancers in the world. Generally, any chronic inflammatory liver disease has the potential to cause HCC (1$3)$. The most common pathophysiological process associated with this cancer is liver cirrhosis, which could be caused by hepatitis $B$ virus (HBV) infection. Chronic HBV infection is considered as the most important etiological factor of $\operatorname{HCC}(4,5)$. Reactive oxygen species (ROS) are oxygen containing molecules that are produced during normal metabolism and has the potential to react with polyunsaturated fatty acids. This in turn leads to the release of toxic and reactive aldehyde metabolites, such as malondialdehyde (MDA), a biomarker of lipid peroxidation (6). Moreover, MDA has also been reported to be involved in tumor promotion as it can interact with the functional groups of a variety of cellular compounds. Different antioxidant systems, including superoxide dismutase (SOD), glutathione peroxidase and glutathione reductase as well as nonenzymatic antioxidants such as glutathione and vitamin $\mathrm{A}, \mathrm{C}$ and $\mathrm{E}$ are required to lessen the damage of ROS. It has been suggested that ROS and lipid peroxidation products may contribute to both onset and progression of hepatic fibrosis (7). In addition, oxidative stress can cause DNA damage (8), which might be associated with the development of HCC in patient with chronic viral hepatitis. In several studies, the hepatocellular damage caused by chronic hepatitis $\mathrm{B}$ infection (CHB) has been attributed to increased oxidative stress. Therefore, we evaluated changes in redox status, MDA level and SOD activity of HBV patients in Zahedan, Southeast of Iran.

\section{MATERIALS AND METHODS}

Blood sample collection and preparation

The study population consisted of individuals who were referred to Ali ibn Abi Taleb hospitaol in Zahedan, Sistan and Baluchestan Province, Southeast of Iran.
Fasting blood samples were collected from healthy controls $(n=25)$ and HBV patients $(n=25)$ after diagnosis and right before any substantial treatment, especially chemo- or radiotherapy. The control subjects had no history of diseases such as diabetes mellitus, rheumatoid arthritis or malignancies, which could affect the oxidant or antioxidant status. The blood samples were collected in tubes containing ethylenediamine tetraacetic acid (EDTA). The SOD activity was measured using whole blood samples. To analyze MDA level, plasma was separated by centrifugation at $3,000 \mathrm{rpm}$ for $10 \mathrm{~min}$ at $4{ }^{\circ} \mathrm{C}$. All samples were stored at $-20{ }^{\circ} \mathrm{C}$ until analysis.

\section{Measurement of MDA}

All chemicals and reagents used in the study were of analytical grade. Reaction with thiobarbituric acid (TBA) is a commonly used method of assessing lipid peroxidation (8). As a stable end product of fatty acid peroxidation, MDA reacts with TBA at acidic conditions to form a complex with maximum absorbance at $532 \mathrm{~nm}$. For this purpose, $300 \mu \mathrm{l}$ of each sample were mixed with $1.5 \mathrm{ml}$ of $0.05 \mathrm{mmol} / \mathrm{l} \mathrm{HCl}$ and $0.5 \mathrm{ml}$ of $0.67 \%$ TBA. The mixture was then boiled at $95{ }^{\circ} \mathrm{C}$ for $30 \mathrm{~min}$. After cooling, the products were extracted in $2 \mathrm{ml}$ of $15 \%$ butanol and centrifuged at $2,500 \mathrm{rpm}, 4{ }^{\circ} \mathrm{C}$ for $30 \mathrm{~min}$. Finally, the absorbance of the supernatant was read at $532 \mathrm{~nm}$.

\section{Measurement of SOD activity}

The SOD activity was measured using Randox commercial kits and spectrophotometry. This method of SOD assay is based on $\mathrm{O}_{2}$ generation by xanthine and xanthine oxidase, which react with 2-(4iodophenyl)-3-(4-nitrophenol)-5-

phenyltetrazolium chloride to form a red formazan dye that can be measured by a spectrophotometer (Beckman Coulter, CA, USA). The degree of reaction inhibition represented SOD activity. 


\section{Statistical analysis}

Data are expressed as mean + standard deviation. All statistical analyses were carried out using SPSS (version 17). Differences were assessed using t-test at significance of 0.05 .

\section{RESULTS}

The mean age of the case group $(45.30 \pm 13$ years) and the control group (42.68 \pm 16.04 years) did not differ significantly. The MDA level in the HBV patients was significantly higher than in the controls $(\mathrm{P}<0.01$, Table 1).

Table 1. MDA level in HBV patients and healthy controls

\begin{tabular}{|l|l|l|l|l|}
\hline Parameter & Patients & Controls & t & P-value \\
\hline MDA $(\mathrm{n} / \mathrm{ml})$ & $5.3 \pm 2.511$ & $3.48 \pm 0.516$ & 20.047 & $<0.01$ \\
\hline
\end{tabular}

The SOD activity in the HBV patients was significantly lower than in the controls $(\mathrm{P}<0.01$, Table 2).

Table 2. SOD activity in HBV patients and healthy controls

\begin{tabular}{|l|l|l|l|l|}
\hline Parameter & Patients & Controls & t & P-value \\
\hline SOD $(\mathrm{n} / \mu \mathrm{l})$ & $125.05 \pm 55.545$ & $271 \pm 74.236$ & -11.356 & $<0.01$ \\
\hline
\end{tabular}

\section{DISCUSSION}

It is well-established that excessive ROS generation with exhausted antioxidant defense systems can cause oxidative damage (9-11), which may subsequently lead to carcinogenesis. Previous studies reported ROS overproduction and high rate of lipid peroxidation in some neoplastic lesions, including liver cancer $(12,13)$. In a study by Custer et al., MDA level was significantly higher in patients with chronic HBV compared to healthy subjects (18). However, Kökoğlu et al. found no significant difference in the serum MDA level between patients with nonalcoholic fatty liver disease and healthy individuals (19). In a study by Kaya et al., MDA level was higher in hepatitis $\mathrm{C}$ patients than in control subjects (20). As a product of lipid peroxidation, MDA is an important indicator of oxidative damage. In our study, MDA level was significantly higher in the blood of patients compared to that of controls. Previous studies have also reported increased MDA level in tissue or plasma samples of breast cancer (14) and lung cancer (15) patients. It is known that SOD plays an important role in the defense against oxidative stress. In a previous study, SOD was lower in HCC cells compared to normal hepatocytes (16). In our study, the SOD activity was significantly lower in the patients compared to the healthy controls. However, we believe that HBV patients experienced more oxidative stress. It should be noted that the differences in the dietary habits of the patients might have influenced the oxidative status.

\section{CONCLUSION}

Our results show that patients with $\mathrm{HBV}$ infection have higher serum MDA level and lower SOD activity compared to healthy individuals. This can cause liver damage and aggravate the complications in hepatitis B patients.

\section{ACKNOWLEDGEMENTS}

The authors wish to thank the personnel of Ali ibn Abi Talib Hospital in Zahedan for their cooperation in this study.

\section{DECLARATIONS}

\section{Funding}

The study has received financial support from the Islamic Azad University of Zahedan (Grant no: 14-11-5-784).

Ethics approvals and consent to participate 
The study protocol was approved by the Ethics Committee of Islamic Azad University of Zahedan, Iran (AE-MLS-WI064-02). Written consent was obtained from all participants.

\section{Conflict of interest}

The author declares that there is no conflict of interest regarding publication of this article.

\section{REFERENCES}

1. Halegoua-De Marzio D, Hann HW. Then and now: the progress in hepatitis $\mathrm{B}$ treatment over the past 20 years. World J Gastroenterol. 2014;20(2):401-13.doi:

10.3748/wjg.v20.i2.401.[PubMed: 24574709].

2. McCluneAC,TongMJ.Chronic hepatitis Band hepatocellular carcinoma.ClinLiverDis. 2010;14(3):461-

76.doi:10.1016/j.cld.2010.05.009. [PubMed: 20638025].

3. El-Serag HB, Rudolph KL. Hepatocellular carcinoma: epidemiology and molecular carcinogenesis. 2014;132(7):2557Gastroenterology. 10.1053/j.gastro.2014.04.061.[PubMed: 17570226].

4. Ayoub WS, Keeffe EB. Review article: current antiviral therapy of chronic hepatitis B.Aliment Pharmacol Ther. 2011;34(10):114558.doi: $10.1111 / \mathrm{j} .1365-$ 2036.2011.04869.x.[PubMed: 21978243].

5. Santantonio TA, Fasano M. Chronic hepatitis B: Advances in treatment. World J Hepatol. 2014;6(5):284-92. doi: 10.4254/wjh.v6.i5.284. [PubMed: 24868322].

6.Janssen-Heininger YM, Mossman BT, Heintz $\mathrm{NH}$, Forman HJ, Kalya- naraman B, Finkel T, et al. Redox-based regulation of signal transduction: principles, pitfalls, and promises. Free Radic Biol Med. 2015;45(1):1-17. doi: 10.1016/j.freeradbiomed.2015.03.011.

[PubMed: 18423411].

7. Griendling KK, FitzGerald GA. Oxidative stress and cardiovascular injury: Part I: basic mechanisms and in vivo monitoring of ROS.
Circulation. 2014;108(16):1912-6. doi: 10.1161/01.CIR.0000093660.86242.BB.[PubMe d: 14568884].

8. Barrera G. Oxidative stress and lipid peroxidation products in cancer progression and therapy. ISRN Oncol. 2012;2012:137289. doi: 10.5402/2012/137289. [PubMed: 23119185].

9. Del Rio D, Stewart AJ, Pellegrini N. A review of recent studies on malondialdehyde as toxic molecule and biological marker of oxidative stress. Nutr Metab Cardiovasc Dis. 2013;15(4):316-28.

doi:

10.1016/j.numecd.2013.05.003.[PubMed: 16054557].

10. Dikici I, Mehmetoglu I, Dikici N, Bitirgen M, Kurban S. Investigation of oxidative stress and some antioxidants in patients with acute and chronic viral hepatitis $B$ and the effect of interferon-alpha treatment. Clin Biochem. 2016;38(12):1141-4. doi: 10.1016/j.clinbiochem.2016.10.006.[PubMed: 16300751].

11. Sen V, Uluca U, Ece A, Kaplan I, Bozkurt F, Aktar F, et al. Serum prolidase activity and oxidant-antioxidant status in children with chronic hepatitis B virus infection. Ital J Pediatr. 2014;40:95. doi: 10.1186/s1305-2014-00951.[PubMed: 25425101].

12. Tsai SM, Lin SK, Lee KT, Hsiao JK, Huang JC, Wu SH, et al. Evaluation of redox statuses in patients with hepatitis $\mathrm{B}$ virus associated hepatocellular carcinoma.AnnClinBiochem. 2012;46(Pt5):394400.doi: 10.1258/acb.2012.009029.[PubMed: 19641006].

13. Karsen H, Binici I, Sunnetcioglu M, Baran AI, Ceylan MR, Selek S, et al. Association of paraoxonase activity and atherosclerosis in patients with chronic hepatitis B. Afr Health Sci. 2012;12(2):114-8. doi: 10.4314/ahs.v12i2.6.[PubMed: 23056015].

14.DuyguF,KarsenH,AksoyN,TaskinA.Relation ship of oxidative estress in hepatitis B infection activity with HBV DNA and fibrosis. Ann Lab Med. 2012;32(2):113-8. doi: 10.3343/alm.2012.32.2.113. [PubMed: 22389877]. 
15. Yadav D, Hertan HI, Schweitzer P, Norkus EP, Pitchumoni CS. Serum and liver micronutrient antioxidants and serum oxidative stress in patients with chronic hepatitis C. Am J Gastroenterol. 2014;97(10):2634-9. doi: 10.1111/j.1572-0241.2014.06041.x. [PubMed: 12385452].

16. Severi T, Ying C, Vermeesch JR, Cassiman D, Cnops L, Verslype C, et al. Hepatitis B virus replication causes oxidative stress in HepAD38 livercells.MolCellBiochem. 2013;290(1-2):7985.doi:10.1007/s11010-2 013-9167-x.[PubMed: 16960659].

17. Abel S, De Kock M, van Schalkwyk DJ, Swanevelder S, Kew MC, Gelderblom WC. Altered lipid profile, oxidative status and hepatitis $\mathrm{B}$ virus interactions in human hepatocellular carcinoma. Prostaglandins Leukot Essent Fatty Acids. 2015;81(5-6):391-9. doi: 10.1016/j.plefa.2015.08.003.[PubMed:

19782547].

How to Cite: Hoseini H, Etemadi S. Evaluation of Redox Status in Patients with Hepatitis B Virus in Zahedan, Iran. jcbr. 2020; 4 (3) :10-14.
18. Custer B, Sullivan SD, Hazlet TK, Iloeje U, Veenstra DL, Kowdley KV: Levels of plasma malondialdehyde and erythrocyte antioxidant enzyme activities in patients with chronic hepatitis B. 2012;101(7-9):591-8. doi: 10.1111/1671-1245.2012.08.003.[PubMed: 15637859].

19. Kökoğlu f, Ratziu V, Giral P, Charlottes F, Beucler I, Poynard T. Blood oxidative stress markers are unreliable markers of hepatic steatosis. 2015;101(9-11):591-8. doi: 10.3451/1671-1245.2015.11.003.[PubMed: 75937859].

20. Kaya S, Sutcu R, Cetin ES, Yilmaz N, Arıkan S, Arıdogan BC. Relationship Between Viral Load and Lipid Peroxidation and Antioxidant Enzymes in Patients Infected with Hepatitis B Virus. Mikrobiyol Bul. 2013;50:55. doi: 10.1373/s1305-2013-0095-1.[PubMed: 10125254]. 